\title{
Change in Meaning of Brand Personality Characteristics: An Advertising Analysis (An Abstract)
}

\author{
Kaisa Lund
}

\begin{abstract}
Brand personality has become an increasingly important concept within brand theory, and factor-based methods constitute the standard measure in brand personality research. However, questions have been raised about the validity of current factor-based models. This research explores how brand personality characteristics that are salient in verbal and visual advertising content change over time as the brand is extended into multiple product categories. The empirical data are based on a case study of four sub-brands of the personal and skin care brand Nivea, including an advertising analysis and a document analysis. The results show that the meanings of words that represent brand personality characteristics in advertising content shift across different product categories. The study emphasises the problems related to the use of a generalised brand personality scale and develops an alternative methodological approach for brand personality research.
\end{abstract}

References available upon request.

K. Lund $(\bowtie)$

Linnaeus University, Växjö, Sweden

e-mail: kaisa.lund@lnu.se 